\title{
Reading Three Stories of Palm Island
}

\author{
Leigh Dale
}

University of Wollongong

\begin{abstract}
After briefly introducing Palm Island and its history as a place of punishment for Indigenous people, this essay looks at how readers respond to three books about Palm: Thea Astley's The Multiple Effects of Rainshadow (1996), Chloe Hooper's The Tall Man (2008), and Cathy McLennan's Saltwater (2016). Using reviews posted by contributors to Goodreads, I investigate the colocation of terms which recur in positive reviews, in search of a specific form of reading, described here as "absorption." Against the publishing and broader cultural conventions which differentiate fiction from non-fiction, the evidence shows that readers who describe themselves as having become absorbed tend also to praise these books for their truth, regardless of genre. The essay proposes some points of reference for thinking about the reading experience, and concludes by briefly noting the limits of using of genre in marketing, reviewing, and studying books. The essay is built on an awareness of the radical imbalance in the distribution of literacy in the region these books depict.
\end{abstract}

The mainly Aboriginal "settlement" of Palm Island was "established" in 1918, after a cyclone on 10 March that year smashed apart a similar community at Hull River (near Mission Beach). Some in Queensland, notably then "Protector" J.D. Bleakley, had wanted an island prison for Aboriginal and Torres Strait Islander people and ensured land was set aside in 1914 (Watson, 2010, p. 32). The cyclone and its aftermath accelerated the decision: those at Hull River who had not been killed (or just disappeared) were forcibly rounded up and sent to Palm. Strangely enough, this meant that some were returning home (Watson, 2010, p. 35), "most of the people" on Palm Island having been "removed to Hull River settlement" in 1912. ${ }^{1}$ Between 1918 and 1972, there were almost 4,000 such "removals," mainly from Queensland, but also from the Northern Territory and the Torres Strait: "Fear of being removed to Palm Island, from which there was little chance of escape, were passed down through generations of Indigenous people in Queensland" (Watson, 2010, p. 38, 36).

For those who had always been there, the history of kidnapping and exile from Palm had begun even earlier, in 1883 , when eight men and women were seized and forced to become

1 "Establishment of Palm Island," corflute poster, Indigenous Knowledge Centre, Palm Island, Queensland. I thank the IKC for permission to take notes from these sources. 
performers in Barnum, Bailey and Hutchinson's "Greatest Show on Earth" (Watson, 2010, p. 29). ${ }^{2}$ Historian Henry Reynolds, a long-time resident of nearby regional centre Townsville, has called it "an island Siberia": "If you had set out to create a community with problems, if that had been your specific intention, you couldn't have done better than the Queensland government did, inadvertently, on Palm Island" (Special Broadcasting Service, 1993). Yet, as Watson is at pains to point out, Palm Island is also one of Australia's largest Indigenous communities (see also Hooper, 2008, p. 12); for many people, it is home.

The three books I discuss here consider life on Palm Island in the context of its twentiethcentury history, as prison, naval base, mission, administrative showpiece, and holiday resort, as well as being home to Indigenous people from 57 different cultural and linguistic backgrounds. ${ }^{3}$ The first of these books is a novel by Thea Astley, one of Australia's most famous writers. The Multiple Effects of Rainshadow (Astley, 1996) was shortlisted for the Miles Franklin Award, perhaps Australia's most prestigious literary prize, in 1997, and won the Age newspaper's Book of the Year. The title refers literally to the "rainshadow" that affects the Townsville region (Healy, 2016). ${ }^{4}$ But "rainshadow" is also a metaphor: shadows get longer, they shift, they deepen and make it hard to see; violence leaves "shadows" in hearts and minds and voices. The violence Astley writes about is based on two events, one in 1930, the second in 1957. In 1930 Robert Curry (sometimes Currie), a former army officer who was superintendent of the settlement, killed then incinerated his children, blew up some buildings and a boat, shot and wounded the island's doctor and the doctor's wife, then was himself shot and died, events described in detail in a series of stories in the Townsville Daily Bulletin. ${ }^{5}$ In 1957, a strike by Indigenous residents - who kept the settlement immaculate, and produced its food-was broken when a police contingent smashed down doors and took seven strikers away in chains, afterwards exiling them and their families to other "settlements" across Queensland. ${ }^{6}$ Like the shadows of a moving object, violence and exile pivot and spin: exiled

\footnotetext{
2 "1918 Hull River Removals," corflute poster, Indigenous Knowledge Centre, Palm Island, Queensland. Another poster (among 33 depicting the history of the island) shows a picture of eight Aboriginal women and men posing for a photograph in a San Francisco studio in 1892.

${ }^{3}$ Elsewhere this figure is given as 40; it derives from the "national survey" conducted in 1938 and 1939 by Norman Tindale and Joseph Birdsell, which aimed to collect genealogies from Aboriginal and Torres Strait Islander peoples living on missions and "settlements" (or reserves, effectively, open air prisons) across Australia. Information from corflute posters, Indigenous Knowledge Centre, Palm Island.

${ }^{4}$ I thank Mary Vernon for bringing this to my attention, by explaining the weather patterns and geography of the region.

5 See "Palm Island Sensation" (1930), and "The Palm Island Tragedy a Terrible Affair" (1930). Subsequent stories give details on the violence that had already occurred, as part of the coverage of the Inquiry into the killings by Curry (February), the arrest and charging of several persons in relation to Curry's death (April), their trials (June), and the collapse of the charges (August), all from the National Library of Australia's Australian Newspaper Database, http://trove.nla.gov.au/newspaper/ (search "Robert Curry"). Astley clearly had read these news stories, and/or Joanne Watson's 1993 PhD (Watson, 1993); see also "The 1930 Rampage: 'As Straight as a Gun Barrel' " (Watson, 2010, pp. 5575).

${ }^{6}$ Descriptions of these events, along with photographs that confirm that the "settlement" had a military neatness, gardens and carefully swept dirt streets marked out by rows of lime-washed rocks, are in the corflute posters at the Island's Indigenous Knowledge Centre.
} 
to, exiled from Palm, Indigenous people are blamed for violence they have usually been victims of.

Thea Astley shows her characters struggling with history, how to remember it. Her character Mr Vine, an English teacher, writes about the problem in a letter to a former student, Normie Cooktown, whose consciousness is the narrative centre of the novel:

There was a time, Vine wrote, I felt deeply about something - someone, actuallyand I put that down, all of it, as if it were fiction. Oh, I can't tell you the pain and hurt of the reality. But after it was written, and the years had passed, I found I couldn't even remember the faces-the face, to tell the truth-or the words or the events. Not with any clarity, that is. It was as if the whole of that period had lost its reality and become absorbed as fiction and was as fragile and unmemorable as most fiction is. It had ceased to exist. (Astley, 1996, pp. 284-85)

I don't think Astley herself believed fiction is "fragile and unmemorable"-after all, she spent a lot of her life writing it-but I do think she wanted readers to think about how stories can be made to continue, and to resonate, rather than fray and fall apart, becoming illegible. She does that in this novel: helps us to remember, and make us think about memory, by writing fiction. And she uses the word "absorption" to describe the way in which stories become integrated into our bodies, our ways of thinking and speaking.

For most people, a well-told story is a better mnemonic or memory tool than a list of facts, but Normie Cooktown is sceptical about what he calls " 'Fuckin' fiction!' ": “ 'Fuckin' fiction!' Normie said aloud and bitterly, looking around the crowded shanty he shared with his family, four of them in a room twelve by ten' (Astley, 1996, p. 285). But if he's cynical about novels, Normie also realises he has been made stronger by a literary education he hated getting because of his classmates' racism (pp. 179-80): "It done somethin, his eldest brother Manny said. You can talk to the bastards now. You ain't scared" (p. 285). Those "bastards" are white people; Bill Congoo, one of the men exiled from Palm Island as a consequence of the strike in 1957, says of the supervisor whose authority he and others were protesting, "he was a Bastard" (Untitled Poster, n.d.).

Like The Multiple Effects of Rainshadow (1996), Chloe Hooper's The Tall Man (2008) deals with a white inhabitant of Palm Island with authority over the community. Senior sergeant Chris Hurley became the first serving police officer in Queensland to be charged with murder, after the death of a Palm Island resident in custody in 2004. Hooper describes the leadup to the death and the aftermath, including the reaction of Palm Island residents to the news that an initial inquiry had found Hurley innocent of any wrong-doing. She suggests that Hurley had achieved an almost mythic status during his career in isolated places like Palm Island, something she does mainly by using the image of "the tall man." As with Astley's book, the title is both literal and figurative: Hurley is more than two metres tall, so he is (a) tall man. By referring to Hurley's height (the literal), Hooper (figuratively) associates him with the stories of a mythical figure of menace, "the tall man," which circulate in Indigenous communities in north and far north Queensland. Writing more than ten years after Astley, and noting that Palm has 
been "an island of stolen children" (Hooper, 2008, p. 57), Hooper makes the stories of exile and punishment resonate through portraits like this:

One Palm Island woman, Bethel Smallwood, told me that her mother was haunted all her life by not being able to remember her own mother's appearance. She could picture her outline, but could never give her a face. (Hooper, 2008, p. 57)

Memory, memoir, fiction, face. A picture that refuses to appear.

Cathy McLennan's Saltwater (2016) is also about a modern criminal case that is part of the main image of Palm Island in the Australian media: as a place of violence. The book describes McLennan's experiences as a solicitor for the Aboriginal and Torres Strait Islander Legal Service, focusing mainly on her attempts to defend four children who have been charged with murder. But Saltwater begins with a portrait of a very different kind of childhood-her ownand a visit she makes with her primary school class to Palm Island: the culmination of a year of forming friendships through letters, and fundraising. The visit goes badly wrong, then comes right, as the local students meet their visitors not at the airport, nor in the classroom, as had been expected, but after the formalities of the visit have been abandoned. As the visitors play at the island's jetty, slowly the locals emerge, "Looking to each other for joint courage to move forward" (McLennan, 2016, p. 12). From disappointment and disrupted expectations, the excursion is transformed (by McLennan's writing) into a "magical afternoon" in which "we hold hands as we sail through air": "White bodies and black bodies alike glisten with saltwater" ( $p$. 13).

With an average rating close to 4.5 (out of five stars) and generally positive reviews, Saltwater has attracted enthusiastic praise on the book review site "Goodreads" (www.goodreads.com):

This is one of those books you want to read slowly and savour, but you just can't.

And now I'm finished I just keep thinking about it. It's a great read AND its a true story. (Hearney, 2016)

Gripping from start to finish. I couldn't put this book down. Raises so many questions I found myself thinking about the book during reading sessions. The author masterfully pens the book so it feels like a novel and this makes it all the more powerful to realise it is actually a TRUE STORY. (White, 2016)

If there's one book you read this year, make it Saltwater by McLennan. Awesome writing, I just couldn't put it down. The characters come alive and you feel every moment of the story. But that's what's so great about this book, because it's a true story. (Plumber, 2016)

After reading this book (in one sitting), I've felt energised and inspired to create a difference in the world. It's amazing what women can achieve if we set our minds to it!

This was a riveting read. I finished it in one sitting. I'd highly recommend it if it was fiction-the fact that it is non-fiction makes it even more intriguing. (Amanda L., 2016) 
Amanda L., who calls Saltwater "riveting," says that being non-fiction makes the book "even more intriguing"; Jack Plumber (2016) makes the same connection between truth and his connection to the story, "the characters come alive and you feel every moment." He is echoed by Bill White (2016), who says the quality of writing is so high that the book resembles fiction (an interesting yardstick).

While the praise seems be based on the fact that readers found Saltwater "true," that assessment (in my view) misreads memoir, a literary genre with its own craft, as well as McLennan's achievement within it. I am not implying here that McLennan is "lying" or "not telling the truth"; rather, I am saying that prose fiction uses figurative language, language that means a bit more than it says. Take that sentence, "White bodies and black bodies alike glisten with saltwater" quoted above. There is a repetition ("bodies") that is balanced with difference ("White," "black"), so we are encouraged to see black bodies and white bodies as linked, something also suggested by the holding hands. Connection and separation are suggested by the arrangement of words, not just their meaning. This "arranging" extends to sound, also used to suggest similarity and connection: the repetition of "b" in black bodies . . . bodies, then the echo of what is a called a long vowel, "l" in "white, alike," that is then hit with the short "i" in "glisten." More generally the images evoke some stereotypical images of "island paradise" and "beach holidays" - the kind of innocence and fun that children should be having, rather than being threatened by violence or being charged with murder.

McLennan's (2016) supple prose holds us close, so it's not surprising that Bill White should say and Jack Plumber imply that their reading of Saltwater made them feel like they were reading fiction. Ali Fisher agrees:

Don't start this book at night because you CAN'T PUT IT DOWN! It's a thrilling read from start to finish. Seriously, I bought it because I heard the author on the radio (she is a Judge) and I was interested in the issues she raised. I expected a thought provoking read, which it is, but I didn't expect it to be so brilliantly written and thrilling - better than John Grisham in his best book. (Fisher, 2016)

Beth H. (2016) also implies the book is like a novel: "This is a thriller and mystery AND true story. Sounds like it doesn't go together but it does and this is by far the best book I've read for years." 7 These and the comments above link total absorption while reading with truthfulness, then link those two things to something else: resonance, the impact of the book after it has been finished. For Bill White, Saltwater seeps into his life: having asserted that he could not put this "powerful" and "TRUE" book down, he notes that he continued to think about it during "reading sessions" (implying he was meant to be reading something else). Liz Hearney likewise could stop thinking about the book, while for Amanda L., "absorbing" Saltwater is linked explicitly to her sense of herself as a woman, capable of action - "It's amazing what women can achieve if we put our minds to it" (Amanda L., 2016).

${ }^{7}$ Careful readers will note the proximity of the dates of these enthusiastic postings-many occur on August 21. There might have been a connection between the posters, e.g. membership of a reading group, but regardless of this possibility, it is the vocabulary of the praise that concerns me here. 
So, if readers can get absorbed in non-fiction because it's like fiction, what of fiction itself? Do positive reviews of Multiple Effects of Rainshadow (1996) also contain references to being absorbed in the book, and if they do, is that connected to the fact that the book seems true? (And what do we make of that, when it's a novel?) I will come back to that last question in the conclusion; first, to the reviews of Astley's book, which at the time of writing had 79 ratings to Saltwater's 72 (2016), but a lower average of 3.76/5. Nevertheless, reviewers consistently praise the quality of Astley's writing. Kate (2012), who only gave the novel three stars, is nevertheless appreciative, and uses some evocative prose to describe Astley's:

the novel is very engaging and thought provoking-really one of those books that gets under your skin, and makes you think about it for days afterwards. The rhythm of the text is just lovely -the language rich and rolling without extraneous verbiage or filler. (Kate, 2012)

Dyllwinia Peter (2014) likewise makes a link between credibility, and Astley's prose: "it is brutal and honest and believable. And that is why I love Astley-she can create honest, clever fiction from historical events that seems so seamless." The most recent review, by Fiona (2012), links her absorption in the book to Astley's skill: "I couldn't put it down. Harrowing, insightful, multiple points of view so technically accomplished, historically based and relevant today, if you recall Palm Island" (Fiona, 2012).

So it seems that novel readers can link "truth" to technical achievement and reading pleasure; what of those who did not like The Multiple Effects of Rainshadow? Some brief, negative reviews note the failure (or refusal?) of the reader(s) to become absorbed, although in one case the reader gets stuck in and finishes the book because she is travelling:

A little difficult to get into at the beginning. (Mandy, 2012)

Struggled with this, in the end decided there are too many other books out there

... the style made it difficult for me to follow. (Powell, 2014)

This was difficult to get into since none of the characters were particularly appealing. However, I persevered mainly because I had little else to read on a long car trip. (Mary Ann, 2014)

When "absorption" does not occur, the qualities that "absorbed" readers discern, notably Astley's prose style, are not remarked on. That said, Mary Ann-who overcame that "difficult" beginning and ultimately gave the book four stars-describes the novel as a "finely woven, multi-faceted tale," suggesting that it is possible to appreciate Astley's style whilst not becoming "lost" in the book (although there is no praise for authenticity). Perhaps most telling is a negative review from Barry (2013), which sees neither style nor truth in what is described as "[a]n odd book that spans 20 or so years." 8 These findings go a small way towards bearing out the convictions of those researchers who have found "that the real-world truth value of a story has little impact on the extent to which readers become engaged in it, enjoy it, and are affected by it" (Green, 2004; see also Hartung, Hagoort, Willems \& Withers, 2017; Nahari,

\footnotetext{
${ }^{8}$ Barry, though, does give the book four stars, suggesting that reviewers vary widely in how they perceive star ratings: reviewers who were much more positive only gave the book three or even two stars.
} 
Glicksohn \& Nachson, 2010). What, then, of the most popular of these books, Chloe Hooper's Tall Man (2008), which is closest to its subject in terms of time?

With 1886 ratings and 176 reviews on Goodreads, along with a stellar track record in prizes, this book has a much higher profile and is the most likely way a reader could encounter Palm Island. In the context of my question about whether there is a relationship between the impression of plausibility and a particular kind of reading, what is eye-catching are the (admittedly) small number of reviewers who use the word "novel" to describe Hooper's (2008) book; like the readers of McLennan's Saltwater (2016), these reviewers link similarity to fiction to "absorption" while reading. For example, Julia (2013) says, "I read this years ago and still find myself returning to the novel on a regular basis," showing how absorption makes a book linger; she goes on to use the word "novel" twice more in a one-paragraph review. Eli (2012), who like Julia gives The Tall Man five stars, says "A great non-fiction novel." Rebecca McNutt (2016) calls it a "true crime novel" and rates it five stars (although in terms of "shelves," or categories, she lists it as "non-fiction" and "true crime"). Jacqueline says that "I read a lot of true crime novels and this was by far one of the best I've stumbled upon in quite some time" (2015). Whereas as the quality of Astley's novel is linked to truthfulness, Hooper's accomplished style-and, we remember, McLennan's-lead enthusiastic readers to note the resemblance of what they are reading to fiction.

I should also note that many reviewers say The Tall Man (2008) is a difficult read emotionally. Three reviewers, all of whom rated it five stars, are representative:

Quotes on the cover use words such as "riveting," "engrossing" and "powerful" and I can add no better adjectives. I was hooked from the first page, captivated not just by the story itself but by Hooper's writing style. (D.A. Cairns, 2010)

Blimey, this book had quite a profound effect on me, and is a searing indictment of modern day Australia. ... Hooper's book is well-written, clear, concise, and as the blurb on the back of my copy says, she shows 'admirable restraint' to let the story speak for itself. (Manwaring, 2009)

It's rare that I absolutely tear through a book but I genuinely couldn't put The Tall Man down. This is a properly, important story and Chloe Hooper tells it with nothing but subtlety and grace. (Sady, 2012)

Nothing in these comments suggests that becoming engrossed in a book means the reader becomes unable to reflect on its contents. On the contrary, many reviewers comment both on their absorption in The Tall Man, and being driven to think not just about the specific situation it depicts, but the more general and devastating effects of inequality in modern Australia: "I felt myself drawn inexorably into the human tragedy as the story unfolded" (Stewart, 2013, p. 2).

As a website, Goodreads mediates between reading, usually private, and describing that experience to others. It enables contributors to verify part of their identity: as an absorbed, discerning, knowledge-seeking reader. It is also different from the book club or the classroom, in that there is no way of responding to comments other than through proximity to dissenting or concurring views. In that respect, the site models the challenge of "making up your own 
mind" in the light of, say, Barry's (2013) assessment of Astley's novel as an odd book and Fiona's (2012) assertion that she could not put it down. (That it is alright not to get absorbed in Goodreadsland might explain why some readers unashamedly post reviews and ratings of books they admit to not having read much of.) But if the reviews become evidence of a significant event, it is notable how short most are. This brevity stands in contrast to the intensity that is described; long reviews, though, rarely speak of absorption in the same way, often being summaries that make no mention of the actual experience of reading.

\begin{abstract}
When I was young, I was nearly impossible to rouse from my reading. Alive to the book and dead to the world, I read with an intensity and focus now unimaginable to me. I remember this fact, but little of the feeling. What was I hearing, seeing, and sensing as I shut out the world? Now, decades later, on the far side of a literary education, I feel no better equipped to answer this simple question-(Grobe, 2016) ${ }^{9}$
\end{abstract}

In looking at reviews of books about Palm Island, I have been focused on identifying a kind of reading often described as "getting lost"; this mode or process of "absorption" is associated with loving a book. Not everyone who likes a book gets absorbed, but no reviewer mentions having been absorbed then says they didn't like the book. "Absorption" is associated with intense focus on an object complemented by losing awareness of what else is around ussound, movement, other objects. For those reading silently but visually (as opposed to reading aloud or with hands, as for braille), the eyes seem to contract their focus to the words, the ears to close over. This seems to me to be experienced as a two-way flow, of reader into book and book into reader, so what appeals to me about "absorption" as a word for describing an intense reading experience is its ambiguity: it can refer either to "the process of absorbing or the state of being absorbed" (Collins, 1998).

Reading researcher Melanie C. Green (2004), attempting to identify conditions or triggers for absorption-her preferred term is "transportation" - in a short story, argues that "individuals who were more transported thought that the story was more like real life" (p. 262; see also p. 257). This might lead us to conclude that realism is the definitive mode for prompting absorption-but millions of readers of Harry Potter books might think we are wrong; so, too, the reviewers who liked Astley's novel. In any case, "being like real life" is not quite the same as being true. Our own thoughts and impressions are not presented in a straight narrative line-our attention wanders, we think of the past, future, present in a jumble; we do not tell stories using the conventions of the realist novel, with coherent characters behaving sensibly. We tell and hear stories using fragments, moments, vignettes. But if we are nevertheless prepared to consider the possibility that getting absorbed in a book leads the reader to think the book is "true" in some sense, then responses that seem to indicate contradictory or even confused judgements (in terms of genre) start to seem both coherent and evidential, even when they ascribe truthfulness to fiction.

\footnotetext{
${ }^{9}$ As it turns out Grobe has no interest in answering his question as his essay is about Gatz, a theatre event in which F. Scott Fitzgerald's The Great Gatsby is read whilst the events being described are performed alongside a reader/narrator who is increasingly absorbed in the novel he is reading.
} 
Why do reviewers use truth as part of their positive evaluations of a book, across genres? This might reflect the fact that "Truth" is a readily available (if inaccurately applied) cultural category that can be used to confer authority on books. What I mean by that is that when we say something is "true," we are asserting that it is valuable. As readers, we are also implying that our time spent reading that book was well spent (as opposed to goofing off with Harry P.). Put simply, I am speculating that claiming a book is true is a way of making sense of having been absorbed. And the consequences of absorption? Even the tiny sample used here-203 reviews for Hooper, 23 for McLennan, just eight for Astley-bears out the argument of Green (2004) that there is a relationship between the judgement that a book is authentic, pleasure in reading, and a consequent (re)alignment of values between reader and text, one that the reader themselves might not be fully conscious of having experienced. She notes research affirming that "individuals who are transported into a narrative world are likely to change their real-world beliefs and attitudes in response to information, claims, or events in a story" (Green, 2004, p. 248). Again, I want to use a "counter" example, a reader who failed to become absorbed: Barry, whose words I would prefer not to quote, but whose comments suggest he was bewildered by Astley's stories of Palm Island. Unable to understand the novel, he is unable to understand why Astley was interested in her subject. If Gila Ashtor (2016) is correct to conclude her essay on queer reading by asserting that difference (reading) can be "constitutive of attachment," and that "we learn from those who help us survive our questions by inviting us into their own," this opens up a way of believing also that we might read not only to recognise what we already know but to establish new relationships. New stories become narrative pathways through cultures, thereby enabling the formation of new versions of our selves. But it seems that such transformations can happen not only through reading truth but also through reading fiction (as Astley implies) - albeit only if we become absorbed in the book we are reading.

In the light of this argument, there are implications for reading as education, as well as the categorisation and selection of books in shops, libraries, and schools. First, in relation to education, we might consider the possibility that forms of reading that rely on establishing critical distance might be undoing the impact of reading that teaching is thought to promote. If Green (2004) is right about the effects of an absorbed reading, then reading itself might be sufficient as an educational activity, without all the apparatus of testing that accompanies it (I do not say the same for writing). At the very least we can ask, is enough attention paid to choosing books that will be absorbing, as opposed to those which are short, or on a particular theme, or just inoffensive? In regard to selecting books for readers as learners, diversity might be crucial to ensuring as many readers as possible have the opportunity to find a book that absorbs them, rather than simply aligning books and readers on the basis of a shared identity, on the assumption that this will ensure reading pleasure. Having access to diversified reading list is part of ensuring a more diverse and therefore more robust cultural ecology. Given the responses from readers to memoir, non-fiction and fiction respectively about their oftenserendipitous encounter, it seems sensible to ask whether the categories in which books are conventionally conceived, published, marketed, reviewed, and read-categories like fiction, 
non-fiction, romance, poetry, for example-might in fact be impediments to, rather than facilitators of, absorbed reading?

Because they can induce absorbed reading, well-written texts can endow places and events with meaning, give authority to experiences and values that might seem too "small" to be "real," things that are "personal" or "provincial." Books are a mechanism for affirmation; and because they operate on a much smaller scale for production than, say, films, they can carry both the weight of the medium and a wide spectrum of interests. If the majority of people living in Australia and the rest of the world are more likely to read books about it than they are to visit Palm Island, then it follows they will get their sense of "what is true" from their relationships with books like those by Astley, Hooper, and McLennan. Reading might be a way to experience a different present, at least for those with no experience of Palm, one which incorporates a (transformative) awareness of the kinds of stories that could and have been told about the island. So it is crucial to note that no reviewer of any of these books benchmarks their assessment of a book's reliability or their reaction to it in general against their knowledge of Palm Island. For those interested in having a quick look around, the Bwgcolman Warriors' "Many a Tribe" (DesertPeaMedia, 2014) a short video had had nearly 20000 hits at the time of writing.

This raises the question, who is able to read these books, in the sense of having the capacity to obtain and the ability to read them? Who might "study" them, where, and how, and who else might tell true stories about Palm Island? There is no Goodreads entry for Straight from the Yudaman's Mouth, the story told by Peter Pryor (1993), the Murri man who was charged with the murder of Robert Curry, to his daughter Renata Pryor. But Palm Island does have mainland visitors, the recent Spring Festival having attracted a good crowd (Wilson, 2017); this might increase, given the Island's "centenary" will be marked next year and that the local council is planning commemorations, in which case, there might well be more stories emerging from Palm Island.

\section{References}

1918 Hull River Removals [Poster exhibit label]. (n.d.). Indigenous Knowledge Centre. Palm Island, Queensland.

Amanda L. (2016, November 3). Re: Saltwater [Community Reviews content]. Retrieved from Goodreads website: https://www.goodreads.com/book/show/31447045saltwater

Ashtor, G. (2016). Two girls2: Sedgwick + Berlant, relational and queer. Postmodern Culture $27(1)$.

Astley, T. (1996). The multiple effects of rainshadow. Ringwood: Viking.

Barry. (2013, June 8). Re: Multiple Effects of Rainshadow [Community Reviews content].

Retrieved from Goodreads website:

https://www.goodreads.com/book/show/2892814-the-multiple-effects-of-rainshadow

Beth, H. (2016, August 22). Re: Saltwater [Community Reviews content]. Retrieved from Goodreads website: https://www.goodreads.com/book/show/31447045-saltwater 
Cairns, D.A. [D.A. Cairns]. (2010, January 3). Re: Tall Man: The death of Doomadgee [Community Reviews content]. Retrieved from Goodreads website: https://www.goodreads.com/book/show/3901371-tall-man

'College Winner - Law, Business and Governance.' [(2015).] Chancellor's Outstanding Alumnus. Retrieved from alumni.jcu.edu.au 28 October 2017.

Collins English Dictionary: Fourth Australian Edition (1998). Glasgow: HarperCollins.

[DesertPeaMedia]. (2014, September 17). Many a tribe by The Bwgcoman Warriors [Video file]. Retrieved from https://www.youtube.com/watch?v=MRg5yM_D1Vk

Dyllwinia, P. [Peter Dyllwinia]. (2014, March 10). Re: Multiple Effects of Rainshadow [Community Reviews content]. Retrieved from Goodreads website: https://www.goodreads.com/book/show/2892814-the-multiple-effects-of-rainshadow

Eli (2012, September 5). Re: Tall Man: The death of Doomadgee [Online forum content]. Retrieved from Goodreads website: https://www.goodreads.com/book/show/3901371-tall-man

Establishment of Palm Island [Poster exhibit label]. (n.d.). Indigenous Knowledge Centre. Palm Island, Queensland.

Fiona. (2012, February 12). Re: Multiple Effects of Rainshadow [Community Reviews content]. Retrieved from Goodreads website: https://www.goodreads.com/book/show/2892814-the-multiple-effects-of-rainshadow

Fisher, A. [Ali Fisher]. (2016, August 21). Re: Saltwater [Community Reviews content]. Retrieved from Goodreads website: https://www.goodreads.com/book/show/31447045-saltwater

Green, M.C. (2004). Transportation into narrative worlds: The role of prior knowledge and perceived realism. Discourse Processes. 38(2), 247-66.

Grobe, C. (2016). On book: The performance of reading. New Literary History 47(4), 56789.

Hartung, F., Hagoort, P., Willems, R., \& Withers, P. (2017). When fiction is just as real as fact: No differences in reading behavior between stories believed to be based on true or fictional events. Frontiers in Psychology 8, retrieved from https://www.frontiersin.org/articles/10.3389/fpsyg.2017.01618/full

Healy, S. (2016, February 6). Townsville basks in the heat of a "rain shadow". Townsville Daily Bulletin. Retrieved from http://www.townsvillebulletin.com.au/

Hearney, L. [Liz Hearney]. (2016, August 21). Re: Saltwater [Community Reviews content]. Retrieved from Goodreads website: https://www.goodreads.com/book/show/31447045-saltwater

Hooper, C. (2008). The tall man: Death and life on Palm Island. Camberwell: Hamish Hamilton.

Julia (2013, July 18). Re: Tall Man: The death of Doomadgee [Online forum content]. Retrieved from Goodreads website: https://www.goodreads.com/book/show/3901371-tall-man

Kate. (2012, January 4). Re: Multiple Effects of Rainshadow [Community Reviews content]. Retrieved from Goodreads website:

https://www.goodreads.com/book/show/2892814-the-multiple-effects-of-rainshadow 
Mandy. (2012, February 28). Re: Multiple Effects of Rainshadow [Community Reviews content]. Retrieved from Goodreads website:

https://www.goodreads.com/book/show/2892814-the-multiple-effects-of-rainshadow

Manwaring, R. [Rob Manwaring]. (2009, August 22). Re: Tall Man: The death of Doomadgee [Community Reviews content]. Retrieved from Goodreads website:

https://www.goodreads.com/book/show/3901371-tall-man

Mary Ann. (2014, July 9). Re: Multiple Effects of Rainshadow [Community Reviews content]. Retrieved from Goodreads website:

https://www.goodreads.com/book/show/2892814-the-multiple-effects-of-rainshadow

McLennan, C. (2016). Saltwater: An epic fight for justice in the tropics. St Lucia: University of Queensland Press.

McNutt, R. [Rebecca McNutt]. (February 19). Re: Tall Man: The death of Doomadgee [Community Reviews content]. Retrieved from Goodreads website: https://www.goodreads.com/book/show/3901371-tall-man

Nahari, G., Glicksohn, J., \& Nachson, I. (2010). Credibility judgments of narratives: Language, plausibility, and absorption. American Journal of Psychology 123(3), 319-35.

Palm Island sensation (1930, February 4). Townsville Daily Bulletin, 6. Retrieved from http://trove.nla.gov.au/newspaper/, 27 October 2017.

Palm Island tragedy a terrible affair. (1930, February 5). Townsville Daily Bulletin, 5. Retrieved from http://trove.nla.gov.au/newspaper/, 27 October 2017.

Plumber, J. [Jack Plumber]. (2016, August 21). Re: Saltwater [Community Reviews content]. Retrieved from Goodreads website:

https://www.goodreads.com/book/show/31447045-saltwater

Powell, G. [Gayle Powell]. (2014, May 24). Re: Multiple Effects of Rainshadow [Community Reviews content]. Retrieved from Goodreads website:

https://www.goodreads.com/book/show/2892814-the-multiple-effects-of-rainshadow

Prior, R. (1993). Straight from the Yudaman's mouth: The life story of Peter Prior: Before, during and after the Robert Curry days: Never told before. Dept. of History \& Politics, James Cook University, Townsville.

Special Broadcasting Service. (1993). Palm Island. [Television program] In Dateline Australia: SBS.

Sady, R. [Reuben Sady]. (2012, February 26). Re: Tall Man: The death of Doomadgee [Online forum content]. Retrieved from Goodreads website: https://www.goodreads.com/book/show/3901371-tall-man

Stewart, K. [Kathy Stewart]. (2012, July 10). Re: Tall Man: The death of Doomadgee [Online forum content]. Retrieved from Goodreads website:

https://www.goodreads.com/book/show/3901371-tall-man

[Untitled Poster] (n.d.). Indigenous Knowledge Centre. Palm Island, Queensland.

Watson, J. (1993). Becoming Bwgcolman: Exile and survival on Palm Island Reserve, 1918 to the present (Doctoral Dissertation). University of Queensland, Brisbane.

Watson, J. (2010). Palm Island through a long lens. Canberra: Aboriginal Studies Press.

Wilson, A. (2017, September 20). Dancing, Food and Lots More. Palm Island Spring Festival Popular. Koori Mail. p. 31. 
White, B. [Bill White]. (2016, August 21). Re: Saltwater [Community Reviews content]. Retrieved from Goodreads website:

https://www.goodreads.com/book/show/31447045-saltwater 